\title{
ReAMing OF Very PRECISE AND DEeP HOLES WiTh CERMET REAMER
}

\author{
Jaroslava Fulemova \& Jan Rehor
}
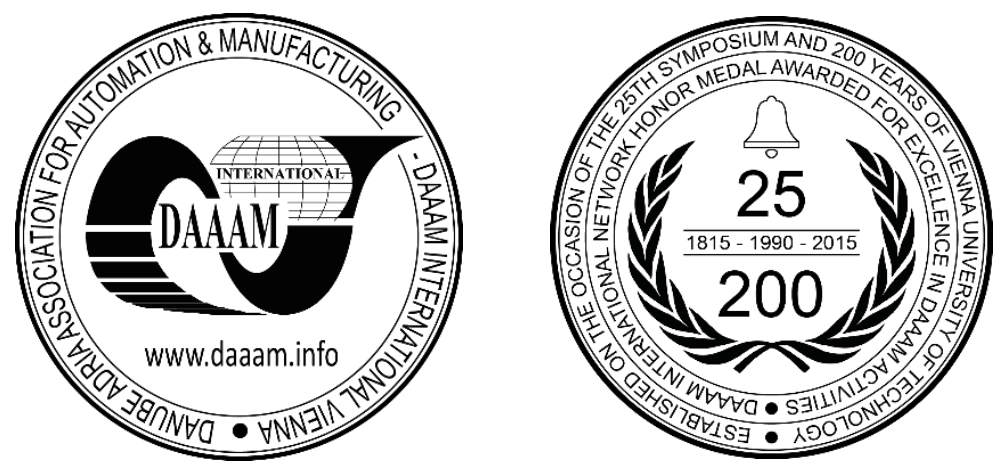

This Publication has to be referred as: Fulemova, J[aroslava] \& Rehor, J[an] (2016). Reaming of Very Precise and Deep Holes With Cermet Reamer, Proceedings of the 27th DAAAM International Symposium, pp.0275-0282, B. Katalinic (Ed.), Published by DAAAM International, ISBN 978-3-902734-08-2, ISSN 1726-9679, Vienna, Austria DOI: $10.2507 / 27$ th.daaam.proceedings.041

\begin{abstract}
Reaming is a technology which is ranked among finishing machining. Reamers are usually tools with one or more teeth. Teeth can be made from different cutting materials. The most common cutting materials for reamers are HSS and Sintered Carbide (SC) with or without coated thin layer. Less frequently used cutting materials are Cermet, CBN and PKD. During reaming, the basic criterion is quality of reamed hole with regard to ensure the optimal level of technology - economy criteria of machining process. It means tool life, productivity of machining process, cost of reaming a hole, etc. Selecting of cutting material has to match the requirements which are mentioned above. This article deals with application cermet reamers in comparison with SC reamers during reaming a hole which is 8D deep and is produced in accuracy class H6. This hole can be found on VDI tool holder. Further, article describes problems which were caused by SC reamers and successful solution with cermet reamers.
\end{abstract}

Keywords: reaming; cermet; sintered carbide; tool life; VDI tool holder.

\section{Introduction}

As was mentioned above reaming is finishing technology. In most cases it is last technological operation. Nevertheless there are situations, when there is demand for more precise holes, where it is necessary to use the other technological operations like grinding, rolling, honing, etc. Drilling and boring precedence reaming and they are operations which influence final accuracy parameters of reamed hole. If there is something wrong like machining parameters, technology, geometry of cutting tools, etc. the reamer is not able to improve geometry and accuracy of produced hole. Drilling is roughing technology, boring and reaming improves size, roughness and geometry.

\subsection{Problem statement}

This article is based on diploma thesis [1], which was solved in cooperation with a Czech company. The company is producer of engineering components and also produces its own tools. A part of their production is VDI tool holders. Production process consist a lot of technologies and one of them is very difficult. Namely it is reaming a hole $\varnothing 8 \mathrm{H} 6$ and deep $69 \mathrm{mmm}$. The main problems are: 
- tool life of the cutting edge is between $50 \div 300$ pieces per a reamer

- excess of criteria value Ra which is set up on $0.8 \mu \mathrm{m}$

- excess of rotational accuracy criteria value which is set up on $0.05 \mathrm{~mm}$

These problems cause:

- low reproducibility of production

- low reliability of cutting process

- higher costs on tool

- waste of the time

- a lot of nonconforming products

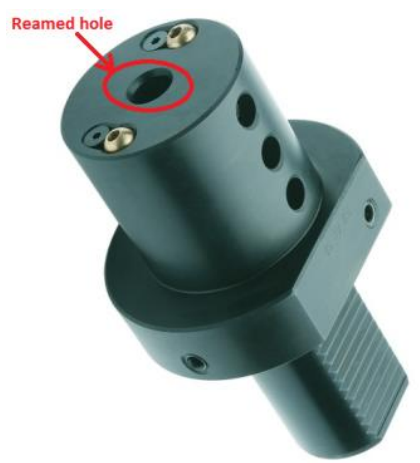

Fig. 1. VDI tool holder [2]

Specifications of process parameters, which are realized in the company, are in the Table 1.

\begin{tabular}{|c|c|c|c|c|c|c|c|}
\hline \multirow{2}{*}{ 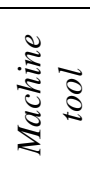 } & \multicolumn{2}{|c|}{ Type } & Name & $\begin{array}{c}\text { Fabrication } \\
\text { year }\end{array}$ & Number of axis & $\begin{array}{c}\text { Power of } \\
\text { spindle [kW] }\end{array}$ & $\begin{array}{c}\text { Spindle speed } \\
{\left[\mathrm{min}^{-1}\right]}\end{array}$ \\
\hline & \multicolumn{2}{|c|}{$\begin{array}{l}\text { Vertical machining } \\
\text { centre }\end{array}$} & $\begin{array}{l}\text { AXA- } \\
\text { DBZ }\end{array}$ & 2005 & 3 & 13 & $30 \div 6000$ \\
\hline \multirow{2}{*}{$\overrightarrow{8}$} & Type & $\begin{array}{c}\text { Cutting } \\
\text { material }\end{array}$ & Coating & $\begin{array}{c}\text { Number of } \\
\text { teeth }\end{array}$ & Cooling & $\begin{array}{c}\text { Cutting speed } \\
{[\mathrm{m} / \mathrm{min}]}\end{array}$ & $\begin{array}{c}\text { Feed rate } \\
{\left[\mathrm{mm}^{\left.-\mathrm{rev}^{-1}\right]}\right.}\end{array}$ \\
\hline & Solid & $\begin{array}{l}\text { Sintered } \\
\text { Carbide }\end{array}$ & TiAlN & 6 & $\begin{array}{c}\text { Inner, 30bar, } 8 \% \\
\text { concentration }\end{array}$ & 80 & 0.4 \\
\hline \multirow{2}{*}{$\begin{array}{c}\tilde{\Xi} \\
\vdots \\
0 \\
\vdots \\
0\end{array}$} & Material & $\begin{array}{c}\text { Heat } \\
\text { treatment }\end{array}$ & \multirow{2}{*}{ 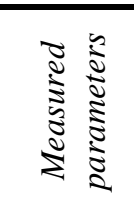 } & $\begin{array}{c}\text { Diameter } \\
{[\mathrm{mm}]}\end{array}$ & $\begin{array}{c}\text { Depth of the } \\
\text { hole [mm] }\end{array}$ & $\begin{array}{c}\text { Surface } \\
\text { roughness }\end{array}$ & $\begin{array}{c}\text { Rotational } \\
\text { accuracy }[\mathrm{mm}]\end{array}$ \\
\hline & $\mathrm{C} 45$ & $\begin{array}{c}\text { Soft } \\
\text { annealing }\end{array}$ & & $8 \mathrm{H} 6$ & 69 & $\mathrm{Ra}=0.8$ & 0.05 \\
\hline
\end{tabular}

Table 1. Specified parameters for reaming the hole

\subsection{Literature research of specified problems}

Based on problems, which were specified in the chapter 1.1., and on 3 questions was did literature research to find out a solution.

\begin{tabular}{|l|l|}
\hline Question: & Solution: \\
\hline Why is the tool life so low? & $\begin{array}{l}\text { Check the type of tool wear. } \\
\text { Change cutting conditions. } \\
\text { Choose different type of grade. } \\
\text { Choose different type of cutting tool material. } \\
\text { Change pressure of inner cooling. }\end{array}$ \\
\hline \multirow{2}{*}{ Why is excessed value Ra? } & $\begin{array}{l}\text { Check the type of tool wear. } \\
\text { Change cutting conditions. } \\
\text { Change geometry of tool. }\end{array}$ \\
\hline \multirow{2}{*}{ What can cause higher value of rotational accuracy? } & $\begin{array}{l}\text { Check the type of tool wear. } \\
\text { Change tool holder. } \\
\text { Choose tool holder with possibility to regulate eccentricity. }\end{array}$ \\
\hline
\end{tabular}

Table 2. Questions which can help solve the problem [3] and [4] 
Tool life is parameter expressed in minutes, metres or number of pieces. If we measure tool life we have to check type of tool wear. During machining soft or stainless steels the main problem is formation BUE. BUE is type of adhesion when small pieces of workpiece stick on a cutting edge. Sometimes we talk about micro-welding. BUE has some advantages but a lot of disadvantages. Protection of cutting edge is ranged among advantages. On the other hand BUE creates new cutting edge which can scratch machined surface. Sometimes the BUE can be broken away and this broken can damage cutting edge. When reaming we can recognize BUE on machined surface, because there can be seen spiral. If we monitor so scratched machined surface we have to measure higher values of surface roughness.[4] and [5] Sintered carbides are very sensitive to BUE. Rehor et al.[6] observed low tool life and higher value of surface roughness of machined surface during reaming cast iron. Reamer was made from sintered carbide and also coated with TiAlN. Photo of the cutting edge with BUE plus differential analysis of the same cutting edge can be seen in the Fig. 2 . In the same figure, there is also a photo of machined surface. Surface was created with BUE on the cutting edge of sintered carbide. Coating protected cutting edge only for 2 metres of machining after that basic substrate was detected and BUE started to grow up. [6]
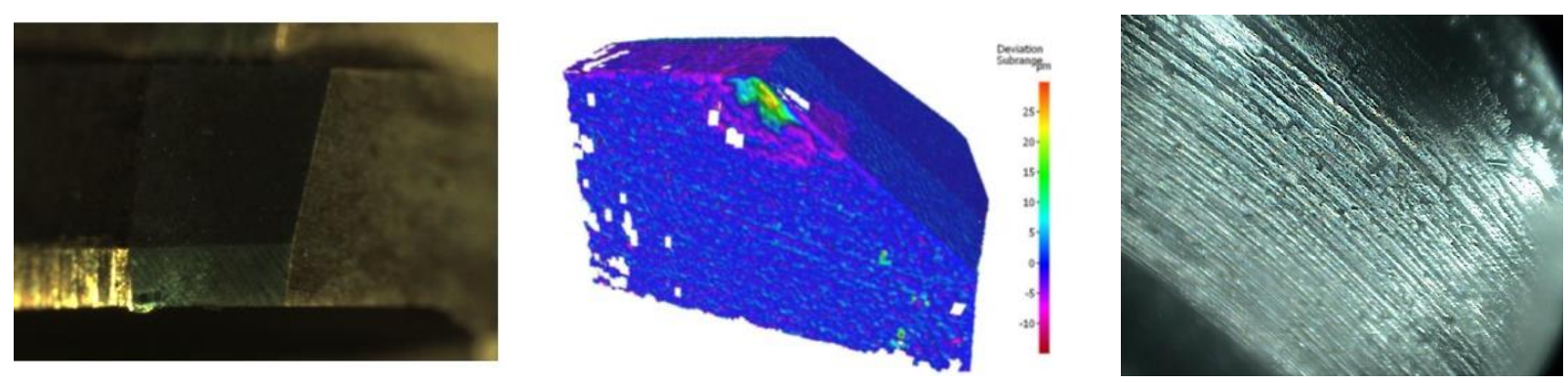

Fig. 2. BUE on the cutting edge of a reamer and picture of reamed hole with BUE on the cutting edge of sintered carbide [6]

So the answer for first and second question is tool wear, to be specific formation of BUE on the cutting edge. World-wide tool producers recommend following:

- Increase cutting speed

- Increase feed rate

- Use coated tool with higher toughness

- Use positive geometry

- When tool life is too low, use huge amount of cooling liquid or not to cool if there is not enough cooling liquid

- $\quad$ Use different kind of cutting material [7] and [8]

Only one possibility, how to improve tool life, was to use different kind of cutting material. Based on literature research was chosen ceremet. Cermet is sintered carbide which is consisted very hard particles of titanium. Cermet is combination of words Ceramic and METal. Cermets of third generation have very high cutting power thanks to increasing content of nitrogen or nitride. Mechanical properties of $\mathrm{Ti}(\mathrm{C}, \mathrm{N})$ cermets are influenced very difficult microstructure. Their microstructure is much more difficult than microstructure of sintered carbides. Microstructure is influenced with original powder, size of particles, lay-out of particles and sintering atmosphere (vacuum, atmosphere $\mathrm{N} 2$ or Ar). Cermets are formed by two phases. First one is very hard phase (TiNC) and the second one is metal binder ( $\mathrm{Ni}, \mathrm{Co}$, or their combination). Cermet is suitable to use for finishing machining. Feed rate can be the same like for cutting ceramic and cutting speed like for sintered carbide with coatings or even higher. Ideal cutting conditions are stable machining process and uninterrupted cut. Cutting edge stays sharp for long time. On the other hand it is very brittle. Cermet is a queen of smooth surfaces. [7], [8] and [9]

Next part of literature research was focused on reducing of rotational inaccuracy. Nowadays, there is necessary to reduce radial eccentricity of rotational tools. There are used more powerful cutting tools, higher cutting speeds and there are also demands for higher quality of surface roughness. These can be influenced with more precise clamping systems and possibility to reduce eccentricity. Ideal clamping system must be solid, stiff, precise and reliable. Choosing of right clamping system means better dimensional accuracy, better geometric tolerations, smoother surface roughness, higher tool life and their economical usage. Classic tool holders like Weldon and whistle notch mountings, ER collet chucks, hydro-plastic tool holder, Tribos system, heat shrinking tool holder, etc. we can call "passive". The second group we can call "active". Active clamping systems are based on passive system, but there is possibility to set the quantity of eccentricity of tool tip up to micrometers. Tool producers of passive systems write to the catalogue information about maximal eccentricity (in micrometers), but this value is not quantified in the field of cutting edge. This value is expressed like $\mathrm{x}$-times tool diameter which is measured from the front part of the tool holder. The values for each tool holder are written in the Tab. 3. The longer tool the higher radial eccentricity. For that kind of tools is good choice to use tool holders with possibility to regulate eccentricity. [10] 


\begin{tabular}{|c|c|c|c|c|c|}
\hline $\begin{array}{c}\text { Type of tool } \\
\text { holder }\end{array}$ & Weldon & ER collet & Hydro-plastic & Heat shrinking & Tribos \\
\hline $\begin{array}{c}\text { Radial } \\
\text { eccentricity }\end{array}$ & $15-20 \mu \mathrm{m}$ & $10-20 \mu \mathrm{m}$ & $\leq 3 \mu \mathrm{m} *$ & $\leq 3 \mu \mathrm{m}^{* *}$ & $\leq 3 \mu \mathrm{m} *$ \\
\hline
\end{tabular}

* measured in the distance 2.5D from the front part of tool holder

** measured on the front part of tool holder

Table 3. Radial eccentricity of each tool holder [10]

System for regulation eccentricity was firstly patented by Robert E. Blades in 1956. This system is called Compensation tool holder and was solving regulation of tool eccentricity which was clamped in three-jaw chuck. Systems of active tool centring offer tool producers like Mapal, Dihart, Komet, Ham-final, etc. These companies are also specialized in reaming technology and reamers. [10]

\section{Experiment}

Based on literature research and specification of problems were set up the experiment. Experiment was done in two steps. First one was in laboratory conditions and second one was in company on real semi-product. All experiments were done on turn-mill complete machining centre CTX beta 1250 TC 4A. As a workpiece was used block of material C45 (soft annealed) which was clamped into three-jaw chuck. The dimensions of workpice were: $160 \mathrm{~mm}$ diameter and $70 \mathrm{~mm}$ high. There were 93 holes in one workpiece (thickness of wall between holes were $6 \mathrm{~mm}$ ). The machine tool and workpiece with reamer are in the Fig. 3. Chemical composition with microstructure is in Tab. 4.
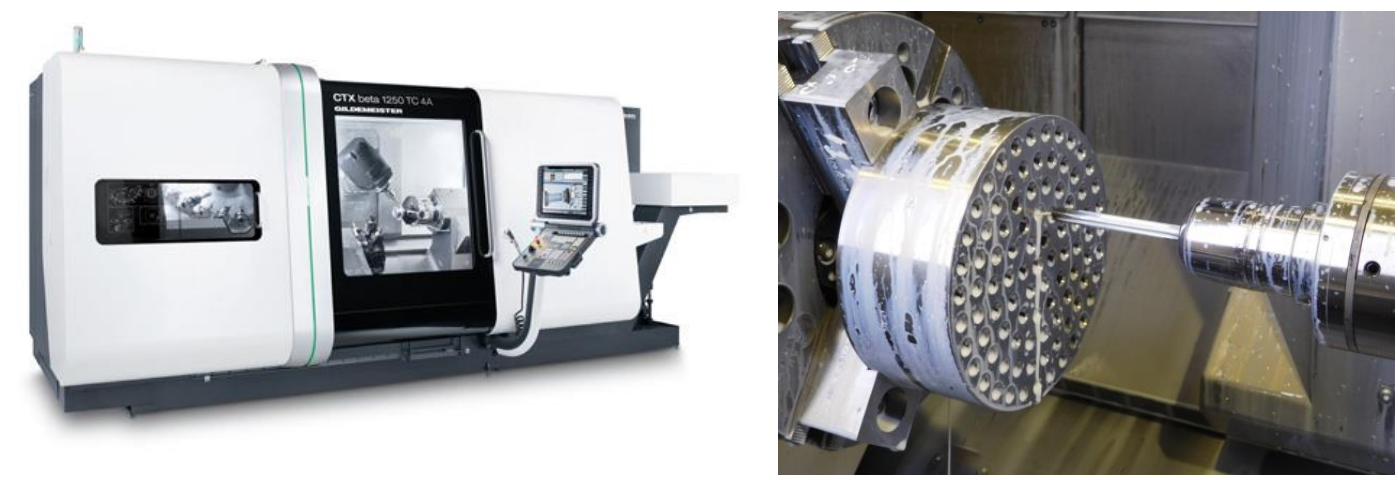

Fig. 3. Machining centre CTX beta $1250 \mathrm{TC} 4 \mathrm{~A}$ and workpiece with reamer

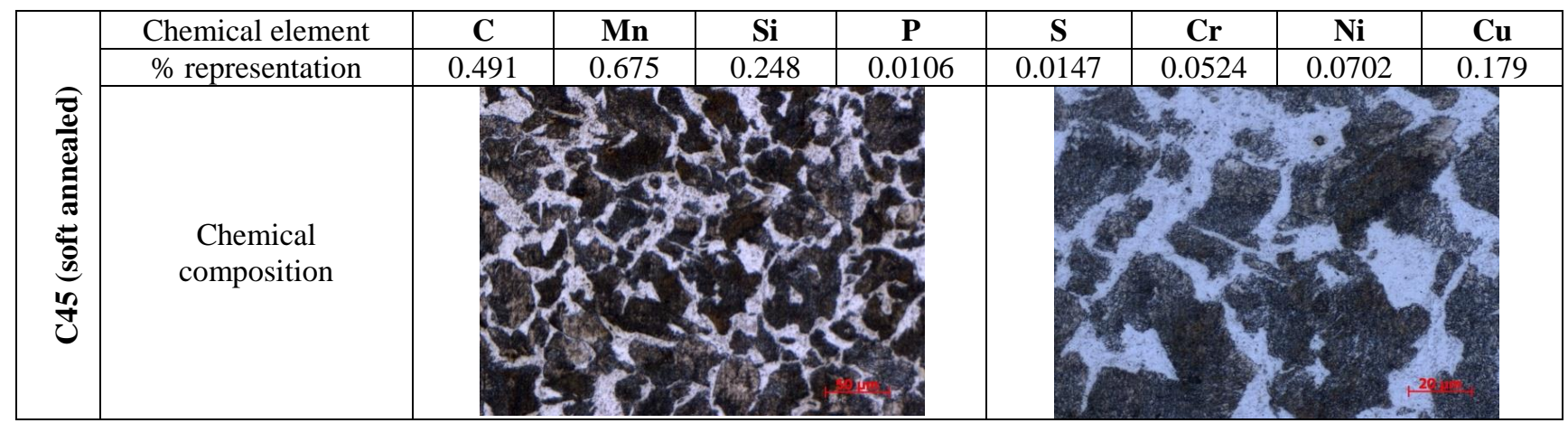

Table 4. Chemical composition and microstructure of steel C45

Further, next very important part is production process of the experiment. In VDI tool holder there is reamed blind hole. Before reaming it is necessary to make few technologies, it means produce hole for reaming. Production process is in the Tab. 5. Because reamed hole is deep, the first step is called spot-drilling. That technology is realized with end mill cutter and size of prepared hole is $\varnothing 7.8 \times 6.5 \mathrm{~mm}$ in the accuracy class ISO $2768 \mathrm{~m}$. Second operation is drilling of the hole $\varnothing 7.8 \times 62 \mathrm{~mm}$. This hole will be reamed and the working allowance for reamer is $0.2 \mathrm{~mm}$. Third step is drilling of the hole $\varnothing 7.1 \times 69 \mathrm{~mm}$. Deeper but smaller hole enables reaming up to depth $61 \mathrm{~mm}$ (generally there should be place between bottom of the hole and lower position of the reamer). Further, there will be other channels for inlet of cooling liquid. Next to last step is chamfering. This technological operation should not be omitted! Last operation was the subject of the experimental research. Plan of the experiment (further specification of the technology nr. 5) is in the Table 6. 


\begin{tabular}{|c|c|c|c|c|c|}
\hline Nr. of technology & 1. & 2. & 3. & 4. & 5. \\
\hline Technology operation & Spot-drilling & Drilling & Drilling & Chamfering & Reaming \\
\hline Dimension [mm] & $\emptyset 7.8 \times 6.5$ & $\varnothing 7.8 \times 62$ & $\varnothing 7.1 \times 69$ & $60^{\circ} \times 1.5$ & $\varnothing 8 \mathrm{H} 6$ × 61 \\
\hline Cutting tool & End mill cutter & Twist drill & Twist drill & Conical cutter & Reamer \\
\hline Cutting tool material & $\mathrm{SC}$ & SC with TiAlN & SC with TiAlN & $\mathrm{SC}$ & $*$ \\
\hline Clamping system & ER collet & ER collet & ER collet & ER collet & $*$ \\
\hline Nr. of teeth & 2 & 2 & 2 & 4 & $*$ \\
\hline Cutting speed [m/min] & 80 & 50 & 50 & 95 & $*$ \\
\hline Feed rate $[\mathrm{mm} / \mathrm{rev}]$. & 0.1 & 0.1 & 0.1 & 0.02 & $*$ \\
\hline $\begin{array}{l}\text { Pressure of internal } \\
\text { cooling liquid [bar] }\end{array}$ & - & 30 & 30 & - & $*$ \\
\hline
\end{tabular}

*parameters which are subject of the experiment

Table 5. Production process of experiment

Based on literature research and on requirements of the project sponsor the only one possibility how to remove problems with tool life and higher values of surface roughness and rotational accuracy was to find a new cutting tool. Because machined material is very "soft" there was chosen cermet as cutting material. Cermet has better properties than sintered carbide, because it has better tool life and machined surface is smoother (sometimes we says that cermet is a queen of machined surfaces). In addition there cannot be observed BUE on cermet cutting edges.

\begin{tabular}{|c|c|c|c|c|c|c|c|}
\hline Nr. & Cutting tool & $\begin{array}{c}\text { Clamping } \\
\text { system }\end{array}$ & $\begin{array}{c}\text { Pressure of } \\
\text { internal } \\
\text { cooling liquid } \\
{[\mathbf{b a r}]}\end{array}$ & $\begin{array}{c}\text { Radial } \\
\text { eccentricity } \\
\text { on the tip of } \\
\text { cutting edge } \\
{[\boldsymbol{\mu m}]}\end{array}$ & $\begin{array}{c}\text { Cutting } \\
\text { speed } \\
{[\mathbf{m} / \mathbf{m i n}]}\end{array}$ & $\begin{array}{c}\text { Feed rate } \\
{[\mathbf{m m} / \mathbf{r e v . ]}}\end{array}$ & Repetition \\
\hline 1. & $\begin{array}{c}\text { Cermet reamer } \\
\text { (size: } \varnothing 8.009)\end{array}$ & RC tool holder & 30 & 2 & 140 & 0.3 & $2 \mathrm{x}$ \\
\hline 2. & $\begin{array}{c}\text { Cermet reamer } \\
\text { (size: } \varnothing 8.007)\end{array}$ & RC tool holder & 100 & 2 & 140 & 0.3 & - \\
\hline 3. & $\begin{array}{c}\text { Cermet reamer } \\
\text { (size: } \varnothing 8.007)\end{array}$ & Hydro-plastic & 30 & 12 & 140 & 0.3 & - \\
\hline 4. & $\begin{array}{c}\text { Sintered carbide } \\
(\text { size: } \varnothing 8.005)\end{array}$ & RC tool holder & 30 & 2 & 80 & 0.4 & $1 \mathrm{x}$ \\
\hline
\end{tabular}

Table 6. Plan of the experiment

$\mathrm{RC}$ tool holder is tool holder which enables to Regulate Centricity/eccentricity. Clamping system is hydro-plastic and it is mounted on the system of deformation elements. Centricity is regulated with thrust and puller screw.

\section{Experimental results}

Draw the experimental plan (see in the Table 6) was set up to test all possible variants. Number sequence of experiments was randomized. If the tool was clamped in RC tool holder, the radial eccentricity was $2 \mu \mathrm{m}$. The tool clamped in the hydro-plastic tool holder had radial eccentricity $12 \mu \mathrm{m}$. Results were compared in terms of real diameter (see in the Fig. 5) and surface roughness (see in the Fig. 7). Real diameter of the hole was measured with pneumatic measuring system Millimar S1840. Measured places were at the beginning of and on the bottom of the hole. Final value, which can be found in the Fig. 4 is an average value. The red line represents the border (accuracy class H6 means that lower size of the machined hole is $8.000 \mathrm{~m}$ and upper size of machined hole is $8.009 \mathrm{~mm}$ ). Everything what is above these borders is wrong and we call it as nonconformity products. Cermet cutting tool with diameter 8.009 mm produced wrong pieces. So it is not suitable to use the tool with the same dimension like maximal upper size of the hole. What is more, if we look at the real diameter of the hole at the beginning and at the end of machining, we can see that the difference is only $1 \mu \mathrm{m}$. So it means if we produce cermet tool with lower diameter, for example $\emptyset 8.007 \div \varnothing 8.005$, the cermet tool will work properly. Cermet tool, clamped in RC tool holder with pressure of cooling liquid 100bar and sintered carbide tool exceeded upper border only at the beginning of machining. Strictly speaking 7 and 20 pieces of VDI tool holders was wrong. The reamer, which produces almost 190 pieces of VDI tool holders was cermet tool clamped in hydro-plastic tool holder and with pressure of cooling liquid 30bar. How is it possible that the reamer with the same diameter, but clamped in different tool holders, was able to produce products with different results? The pressure of cooling liquid is the answer. To explain this problem in more detail, we need to know other information. For example the way of tool wear. Look at the figure 6, there are 3D models and differential analysis of cutting edges after 11 meters of machining. If we compare these tools (Cermet_8.007_30bar_hydro and Cermet_8.007_100bar_RC) we can find out that tool cooled with 1000bar is extremely worn. A part of cutting edge is missing, so we talk about extremely chipped cutting edge. What has happened? High pressure of cooling liquid in the blind holes caused vibration of the tool. Vibration damaged cutting edge and influenced the quality of machined holes. 


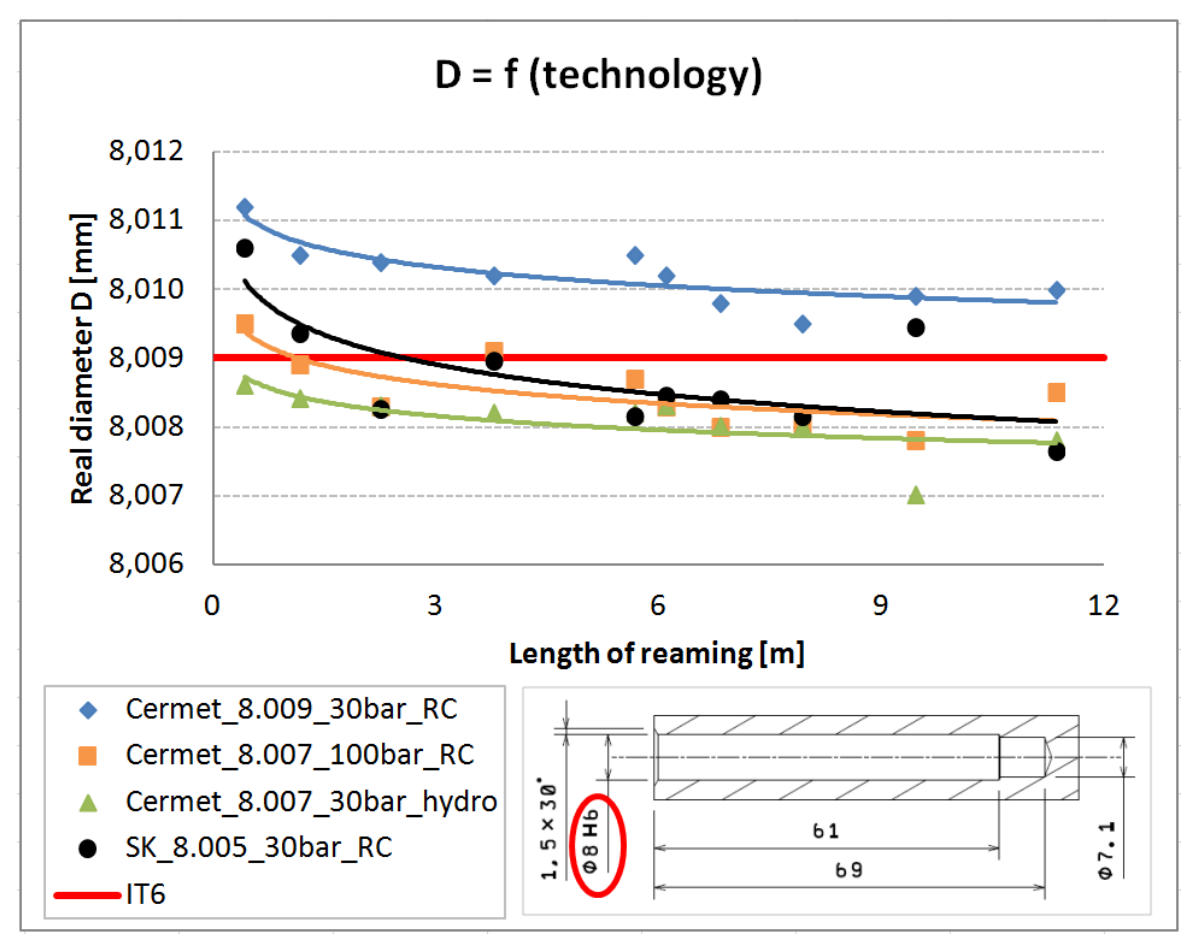

Fig. 5. Influence of technology on the real diameter of machined hole

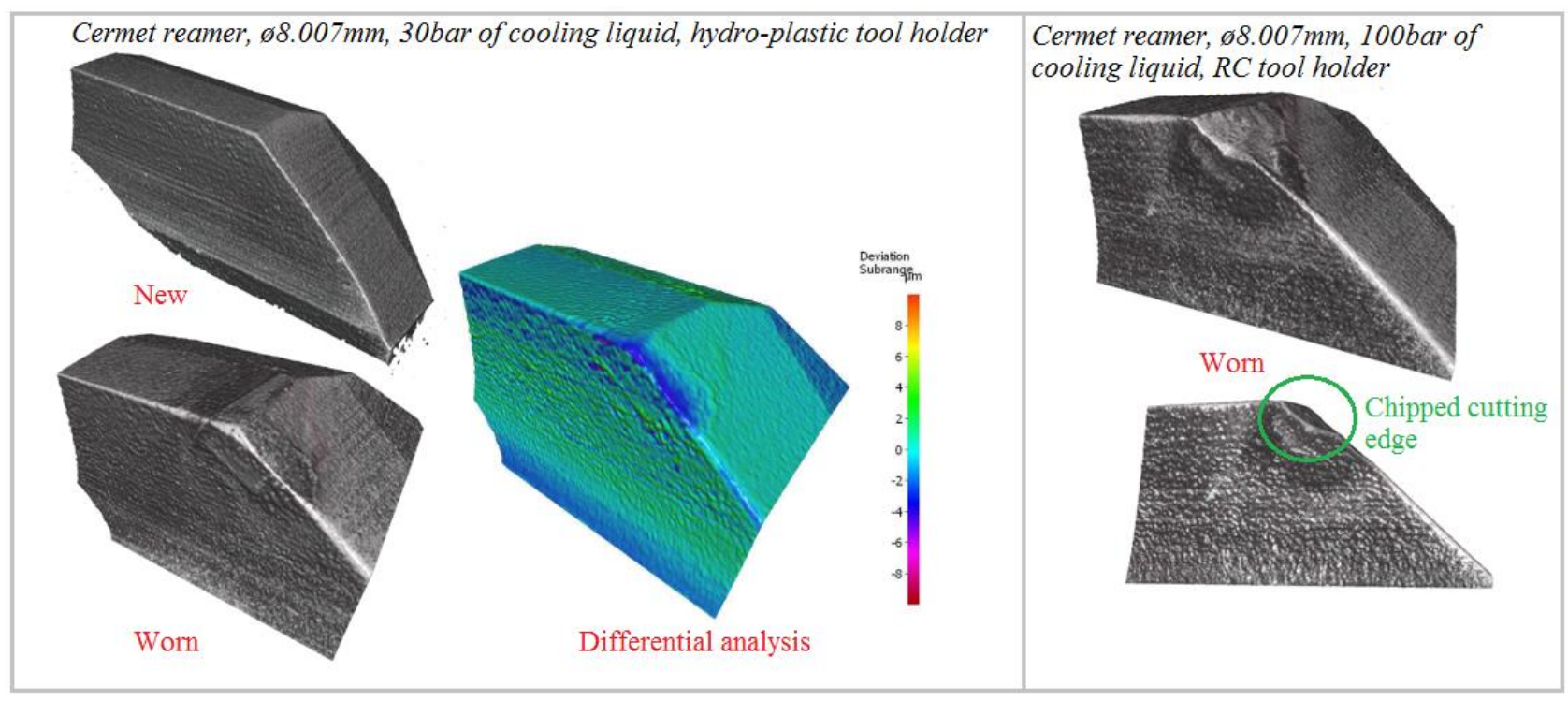

Fig. 6. Comparison of two reamers

The next part of experimental study is in the Fig. 7. There was investigated the influence of technology (it means different cutting tool, clamping system and pressure of inner cooling) on the surface roughness of reamed hole. The worst results were done with sintered carbide reamer. The criteria value of surface roughness $(\mathrm{Ra}=0.8 \mu \mathrm{m})$ was exceeded after $6.5 \mathrm{~m}$ (112 pieces of VDI tool holder). Surface roughness was influenced with cutting edge condition. There was BUE on the cutting edge and this statement is confirmed with pictures from IFM G4 Alicona microscope and optical microscope Multicheck PC 500, see in the Fig. 8. BUE on the cutting edges produces very rough surface, surface looks like scratched, there is usually possible to see helix mark. On the other hand, surface roughness after machining with cermet reamer is very low; the machined surface is very smooth. There are also some differences between results of cermet reamer. The smoother surface roughness was achieved with cermet_8.009_30bar_RC. Results are better than the experiment with the same cutting tool (cermet_8.007_30bar_hydro) which is clamped in the hydroplastic tool holder (we can neglect the influence of different tool diameter). Why are results different? The answer to this question is connected with the system of clamping. Radial eccentricity of cutting tools is different, to be specific one of them has $2 \mu \mathrm{m}$ and the next one has $12 \mu \mathrm{m}$. Radial eccentricity influenced the tool wear of the cutting edges, see in the Fig. 9. The tool wear on the main and second flank face for Cermet_8.007_30bar_hydro is bigger than for Cermet_8.009_30bar_RC. 


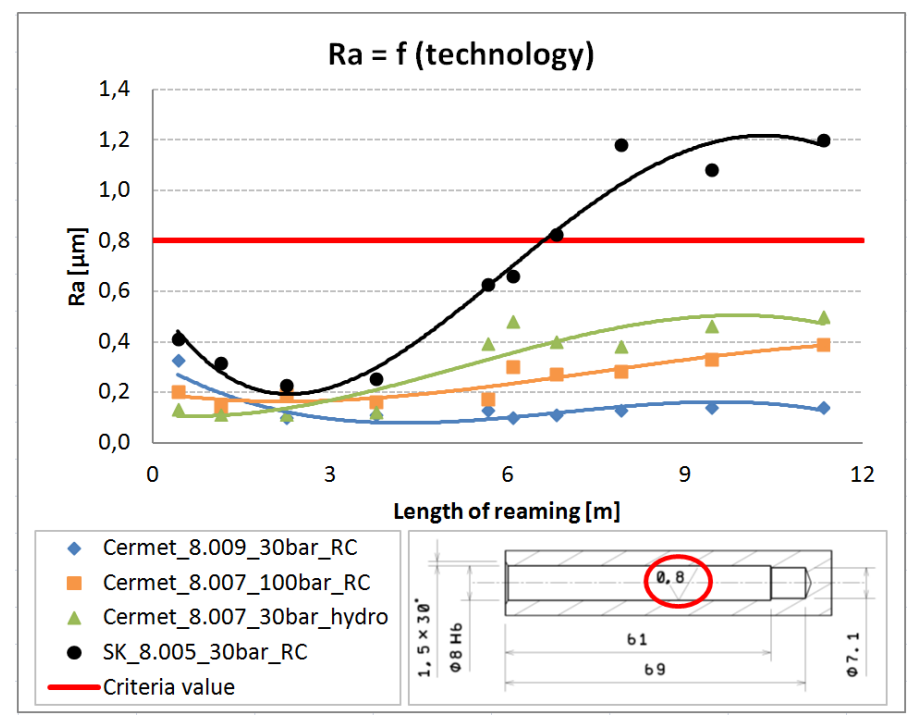

Fig. 7. Influence of the technology on the surface roughness of the hole

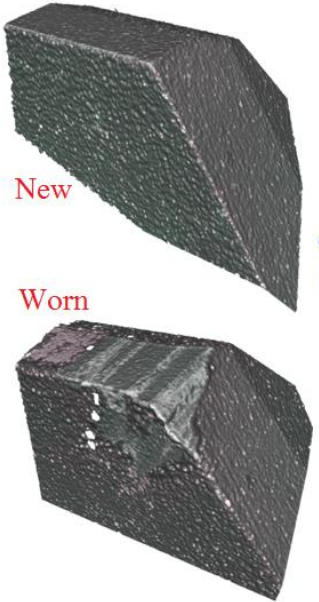

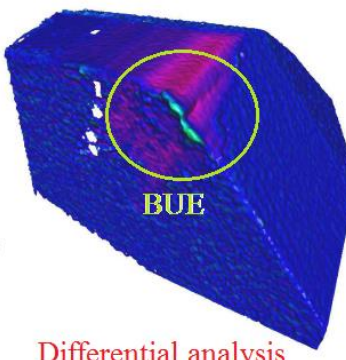
IFM G4 Alicona

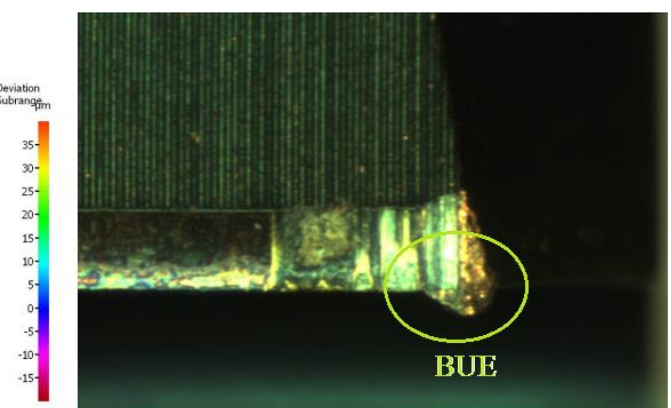

Picture from optical microscope

Fig. 8. BUE on the reamer made from sintered carbide
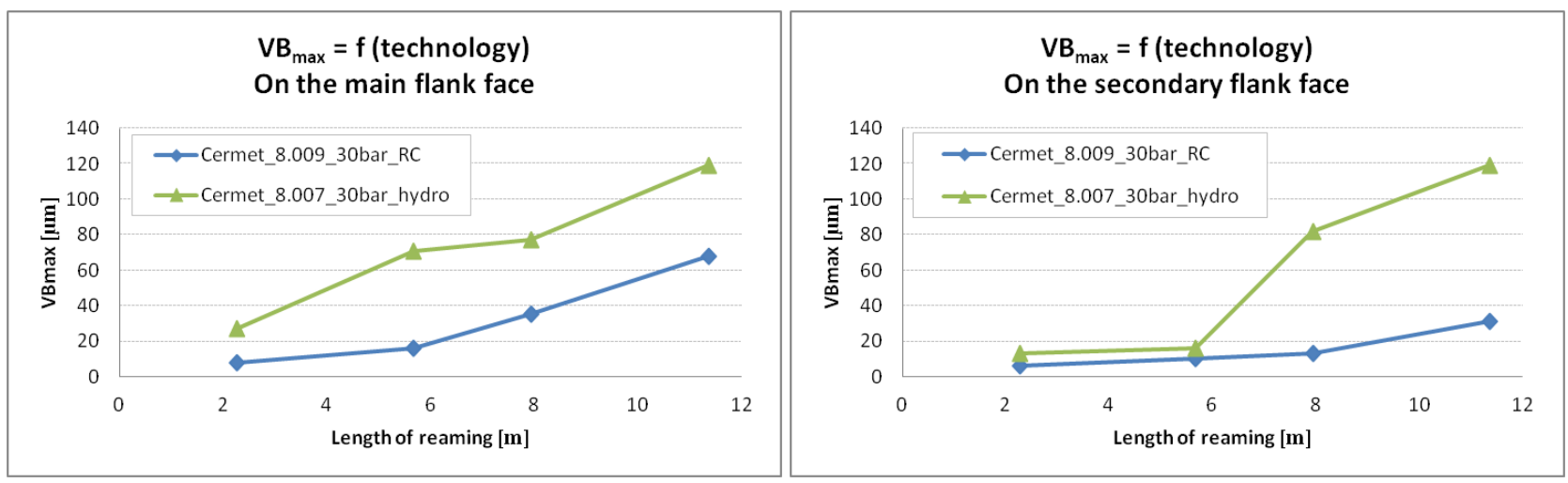

Fig. 9. Tool wear on the main and second flank face for two different clamping systems

\section{Conclusion}

This article was divided into two parts. The first one was focused on literature research and the second one on the solution of problems in real production process. The engineering company is manufacturing VDI tool holders. The tool holder consists a very precise hole and the company solves how to produce it well. Actual production problem is very poor tool life, because they are able to machine about $50 \div 300$ pieces per a reamer. So it means that reliability of production process is very low. The main reason of poor tool life is overrun of criteria value Ra or maximal size of produced hole. The company does not want to machine VDI tool holders on a new machine tool or cooperate with different company. At the beginning there was done literature background research to find out what we can do or 
change. The table of important questions was written down (Table 2). Only two possible solutions could be changed, namely cutting tool material and better clamping system. Sintered carbide reamer was substituted for cermet reamer and there was done a few of experiments. Plan of the experiment can be seen in Table 6. The findings are following:

- Pressure of internal cooling liquid 100bar has negative influence on tool life. High pressure of cooling liquid in the blind holes caused vibration of the tool. Vibration damaged cutting edge and influenced the quality of machined holes. We can see extremely chipped cutting edge in the Fig.6. High pressure of cooling liquid also helped to change the shape and size of a chip, from long cohesive chip to tiny split chip. In the first case, the long cohesive chip stayed at the bottom of the hole (to be specific, it was cram-full in the diameter $6.1 \mathrm{~mm}$ ). In the second case, the tiny split chip was flushed out. The small pieces of the chip could also help to damage the cutting edges. The conclusion is following. Pressure 100bar of internal cooling is not suitable for reaming of this hole type. It is better to use $30 \mathrm{bar}$.

- RC tool holder helped to improve the quality of machined surface (Fig. 7) and reduced tool wear (Fig. 9). RC tool holder regulates the radial eccentricity on the tip of the cutting edge and it has good influence on the cutting process and its results. On the other hand it is suitable to use it in a mass production or there where we need very precise holes. The main disadvantage of RC tool holder is necessity to adjust it right on the machine tool. So it is connected with idle time. For right setting of cermet reamer in RC tool holder is necessary to buy/use a dial indicator with low thrust $(\leq 0.3 \mathrm{~N})$ and scale division $0.002 \mathrm{~mm}$ or lower. RC tool holder improved results of surface roughness and tool life, but if the production charge is low, like in our case (maximal number of workpieces in production charge is 300), it is necessary to count economic return of investments into RC tool holder and accessories. Results of reamer, clamped in hydro-plastic tool holder, are also sufficient.

- Sintered carbide reamer is not suitable for reaming so "soft" workpiece material, because of its inclination to BUE on cutting edge. BUE has negative influence on topography of final surface. Usually we can measure higher values of surface roughness and we can see spiral on machined surface. BUE also influence tool life. There are some general advices how to avoid formation of BUE on cutting edge, but all of them are not possible to use during reaming. In addition, cermet is cutting material which is recommended for finishing technologies and theory says that formation of BUE is less common in comparison with sintered carbide. So the next logical step was to replace sintered carbide as a cermet. Cermet reamer helped to remove all problems during reaming.

The results of the experiments were presented in the company. Also there was done short exhibition of machining with cermet reamer. The company was satisfied and they are going to exchange sintered carbide reamer to cermet.

This real machining problem brightly demonstrated, there are not so many information about influence of all factors (definable and indefinable) on the results of machining very precise holes. So University of West Bohemia in Pilsen, Regional Technological Institute, Laboratory of Metal Cutting decided to focus on this process. So the future steps will be about basic research, it means detailed understanding of reaming process and after that writing a handbook for all who are interested in machining precise holes.

\section{Acknowledgments}

This paper was created due to the project GA ZCU v Plzni: SGS-2016-005 "Research and development for innovation in field of Manufacturing processes - Technology of metal cutting II".

\section{References}

[1] Halaburdova, J. (2016). Improvement of reaming efficiency of a 8D hole it IT6. Plzen. Diploma thesis. ZCU v Plzni

[2] Drzak vyvrtavaci tyce forma E2. MK GROUP CZ s.r.o. [online]. 2014 [cit. 2016-10-01]. Dostupné z: http://mkgroupcz.cz/eshop/kemmler/vdi/drzak-vyvrtavaci-tyce-forma-e2.html

[3] Moravcikova, J. (2015) Cutting Material Influence on the Quality of the Machined Surface. Procedia Engineering [online]. 100, 328-333. DOI: 10.1016/j.proeng.2015.01.375. ISSN 18777058

[4] Piska, M. \& Polzer, A. (2012). On the advanced PVD coatings for threading in austenitic steel. 23rd DAAAM International Symposium on Intelligent Manufacturing and Automation 2012, 2, pp. 831-834

[5] Pilny, L.; Chiffre, de L.; Piska, M. \& Villumsen, M.F. (2012). Hole quality and burr reduction in drilling aluminium sheets. CIRP Journal of Manufacturing Science and Technology [online]. 5(2), 102-107. DOI: 10.1016/j.cirpj.2012.03.005. ISSN 17555817.

[6] Rehor, J.; Fulemova, J.; Rut, D.; Trisková, V.; Kutlwaser, J. \& Kouril, K. (2015). Reaming of very precise holes in hydrostatic component. Manufacturing Technology, 15 (3), pp. 409-415

[7] Zeqiri, H.M.; Qehaja, N.E.; Zeqiri, F.; Salihu, A.H. \& Osmani, H. (2012). Research of flank wear in turning of steel CK60. 23rd DAAAM International Symposium on Intelligent Manufacturing and Automation 2012, 1, pp. 33-36

[8] Identifying and addressing eight common insert failure modes. Seco Tools [online]. (2016) Http: https://www.secotools.com/en/Global/presscentre/Left/Archive-2014/Identifying-and-addressing-eight-commoninsert-failure-modes

[9] Tsuda, K. (2016) History of development of cemented carbides and cermet. SEI Technical Review, (82), pp. 16-20

[10] Matous, P. (2015). Technical illustration and animation of HAM-FINAL RC tool system for practical use. Plzen, Diploma thesis, ZCU v Plzni [11] Schmid, J., Jones, B. \& Braun, J. (2008). The title of the journal paper”, Journal Name, Vol. 24, No. 11, 2008, pp. 1872-1880., ISSN, DOI 